\title{
Long-term safety, tolerability, and antihypertensive efficacy of aliskiren, an oral direct renin inhibitor, in Japanese patients with hypertension
}

\begin{abstract}
Toshio Kushiro ${ }^{1}$, Hiroshige Itakura ${ }^{2}$, Yoshihisa Abo $^{3}$, Hiromi Gotou ${ }^{4}$, Shinji Terao ${ }^{5}$ and Deborah L Keefe
Inhibition of renin, the first rate-limiting enzyme in the renin-angiotensin system, has long been a therapeutic goal for treatment of hypertension. Aliskiren, the first in a new class of oral direct renin inhibitors, has been shown to reduce blood pressure (BP) in several short-term studies. In this 52-week, open-label, multicenter, parallel-group study, the long-term safety, tolerability, and efficacy of aliskiren-based therapy were assessed in Japanese patients $(N=345)$ with mild-to-moderate essential hypertension. The study had two periods: (i) an 8-week, dose-titration period and (ii) a 44-week, fixed-dose period with an optional addition of a diuretic or a calcium channel blocker (CCB). Safety was assessed by monitoring all adverse events (AEs), serious AEs (SAEs), vital signs, laboratory parameters, ECGs, and physical examinations. Efficacy was assessed by trough mean sitting BP and responder rate. Aliskiren alone or in combination with a diuretic or a CCB was well tolerated. No deaths were reported during this study. Nine SAEs were reported, and for three of these, a possible relation to the study drug could not be

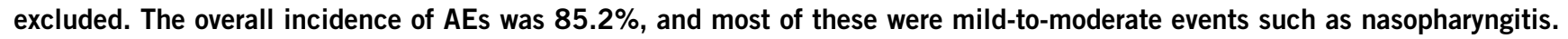
The incidence of suspected study drug-related AEs was $25.3 \%$. A clinically meaningful reduction of $17.6 / 12.8 \mathrm{~mm} \mathrm{Hg}$ from baseline was achieved in the mean sitting BP at the end point with aliskiren, irrespective of the dose and additional treatments. The overall responder rate was $73.3 \%$ at the end point. In conclusion, this first long-term study in Japanese patients showed the safety and efficacy of aliskiren-based therapy in mild-to-moderate essential hypertension.
\end{abstract}

Hypertension Research (2009) 32, 169-175; doi:10.1038/hr.2008.21; published online 23 January 2009

Keywords: aliskiren; direct renin inhibitor; Japanese; long-term safety; renin-angiotensin system

\section{INTRODUCTION}

Hypertension is highly prevalent and a major risk factor for cardiovascular diseases. It is estimated that one-fourth of the Japanese population (35 million adults) have hypertension, but only $20 \%$ of them achieve the blood pressure (BP) goal of $<140 / 90 \mathrm{~mm} \mathrm{Hg}$ in elderly patients and $<130 / 85 \mathrm{~mm} \mathrm{Hg}$ in young and middle-aged hypertensive patients as recommended by the Japanese Society of Hypertension. ${ }^{1-4}$ Hence, there is a clear need for new approaches to treatment of hypertension with drugs that are well tolerated and that can be given once daily to improve patients' compliance and help achieve target $\mathrm{BP} .5,6$

The renin-angiotensin aldosterone system (RAAS) is a critical target in antihypertensive therapy, because it plays a key role in BP maintenance. ${ }^{7}$ Renin has long been recognized as the logical target for the renin-angiotensin system blockade because it corresponds to the first, highly regulated, and rate-limiting step of the system. ${ }^{8}$

Aliskiren, the first in class of orally active direct renin inhibitors, is approved in the United States and the European Union for treatment of hypertension either as monotherapy or in combination with other antihypertensive agents. In clinical studies, aliskiren monotherapy was effective in reducing BP with a tolerability profile comparable to placebo and a safety profile similar to angiotensin receptor blockers (ARBs). ${ }^{9}$ Aliskiren provides additive efficacy, and is well tolerated in combination with angiotensin-converting enzyme inhibitors (ACEIs), calcium channel blockers (CCBs), diuretics, and ARBs. ${ }^{9-12}$

In an 8-week, dose-finding study with aliskiren conducted for the first time in Japanese patients with essential hypertension, once-daily treatment with aliskiren 75,150 , or $300 \mathrm{mg}$ significantly lowered BP with tolerability comparable to placebo. BP reduction was evident from the second week onward and was long lasting and dose-dependent. ${ }^{13}$ After completion of the dose-finding study, patients were invited to enroll in a 12-month, open-label study to assess the long-term safety, tolerability, and efficacy of aliskiren. The results of that long-term study are reported here.

\footnotetext{
${ }^{1}$ Nihon University School of Medicine, Tokyo, Japan; ${ }^{2}$ Department of Internal Medicine, Shinagawa East One Medical Clinic, Tokyo, Japan; ${ }^{3}$ Department of Internal Medicine, Kita Aoyama D Clinic, Tokyo, Japan; ${ }^{4}$ Clinical Research Department, Novartis Pharma KK, Tokyo, Japan; ${ }^{5}$ Biostatistics and Statistical Reporting Department, Novartis Pharma KK, Tokyo, Japan and ${ }^{6}$ Novartis Pharmaceuticals Corporation, Clinical Research and Development, East Hanover, NJ, USA Correspondence: Professor T Kushiro, Nihon University School of Medicine, 1-8-13 Kandasurugadai, Chiyoda-ku, Tokyo, 101-8309, Japan. E-mail: kushiro@med.nihon-u.ac.jp
}

Received 30 May 2008; revised 15 October 2008; accepted 27 October 2008; published online 23 January 2009 


\section{METHODS}

\section{Participants}

Japanese men and women (aged between 20 and 80 years) with essential hypertension (mean sitting diastolic BP $(\mathrm{msDBP}) \geqslant 90$ and $<110 \mathrm{~mm} \mathrm{Hg}$ ), who completed the preceding dose-finding study without safety concerns, were recruited as outpatients from all of the 30 participating clinical centers in Japan. ${ }^{13}$ Patients with severe hypertension (sitting DBP $\geqslant 110 \mathrm{~mm} \mathrm{Hg}$ and/or sitting systolic BP (SBP) $\geqslant 180 \mathrm{~mm} \mathrm{Hg}$ ), secondary or malignant hypertension, type I or type II diabetes receiving insulin or with poor glucose control $\left(\mathrm{HbA}_{1 \mathrm{C}}\right.$ $>8 \%$ ), and serious cardiac, hepatic, renal, or cerebrovascular diseases were excluded. Patients were also excluded if they had a history of hypersensitivity to thiazides, or sulfonamide derivatives, and dihydropyridines.

The study was performed in compliance with the guidelines for Good Clinical Practice and the Declaration of Helsinki Principles of the World Medical Association, and received approval by the Institutional Review Board. All patients gave written informed consent.

\section{Study design}

This open-label, multicenter, parallel-group study was open to participants of a previous aliskiren dose-finding study ( 75,150 , and $300 \mathrm{mg}$ o.d. (once daily)) in Japanese patients with mild-to-moderate essential hypertension. ${ }^{13}$ After the withdrawal of previous antihypertensive medication (during a 1-week washout period), eligible patients entered an 8 -week, dose-titration period followed by a 44-week period of fixed-dose aliskiren with optional concomitant therapy (Figure 1). During the 8-week, dose-titration period, aliskiren was up-titrated from 75 to 150 and $300 \mathrm{mg}$ in a stepwise manner if msDBP was $>90 \mathrm{~mm} \mathrm{Hg}$. In the next 44-week (fixed-dose aliskiren with optional concomitant therapy period), optional addition of concomitant medication (either a diuretic at low dose or a CCB) was used if $\mathrm{msDBP}$ was $>90 \mathrm{~mm} \mathrm{Hg}$ at two consecutive visits. The CCB dose but not the diuretic dose could be subsequently increased if required.
Aliskiren was provided as a film-coated tablet of $75 \mathrm{mg}$ ( 1 tablet $75 \mathrm{mg}$ dose) and $150 \mathrm{mg}$ ( 1 tablet $150 \mathrm{mg}$ dose; 2 tablets $150+150 \mathrm{mg}$ [300 mg] dose). Patients were asked to take the study medication orally with water between 0600 and 1000 hours or after BP assessments on the morning of clinic visits and at least $30 \mathrm{~min}$ before breakfast. Patients were requested to maintain their baseline diet and life style throughout the study period. Salt intake was not restricted.

\section{Assessments}

The primary efficacy variable was the change in msDBP from the pretreatment baseline (baseline of a previous dose-finding study) to the end point (week 52 or last observation carried forward, LOCF). The change in msDBP from the baseline of the long-term study to the end point was also used for the supportive analysis. The secondary efficacy measures were change from the pretreatment and long-term study baselines to the end point in mean sitting SBP (msSBP) and responder rates (defined as the proportion of patients with msDBP $<90$ and/or $\geqslant 10 \mathrm{~mm} \mathrm{Hg}$ decrease from the pretreatment baseline).

Sitting BP and pulse rate were measured at each visit. Sitting BP was measured at trough ( $24 \pm 3 \mathrm{~h}$ post-dose) using an electronic hemodynamometer (Omron HEM-907) after patients had been resting in a seated position for at least $5 \mathrm{~min}$. At each visit, three measurements were taken at 1- to 2-min interval, and the mean of the three values was used for analysis. The pulse rate was measured simultaneously with the first measurement of sitting BP.

Adverse events (AEs) were recorded by the date of onset, severity, and relationship to the study medication. Vital signs, physical condition, body weight, hematology parameters, blood chemistry, and urinalysis were also monitored regularly.

\section{Data analysis and statistical methods}

Descriptive statistics were calculated for all patients, aliskiren doses $(75,150$, or $300 \mathrm{mg}$ ) and optional add-on therapy groups (aliskiren monotherapy,

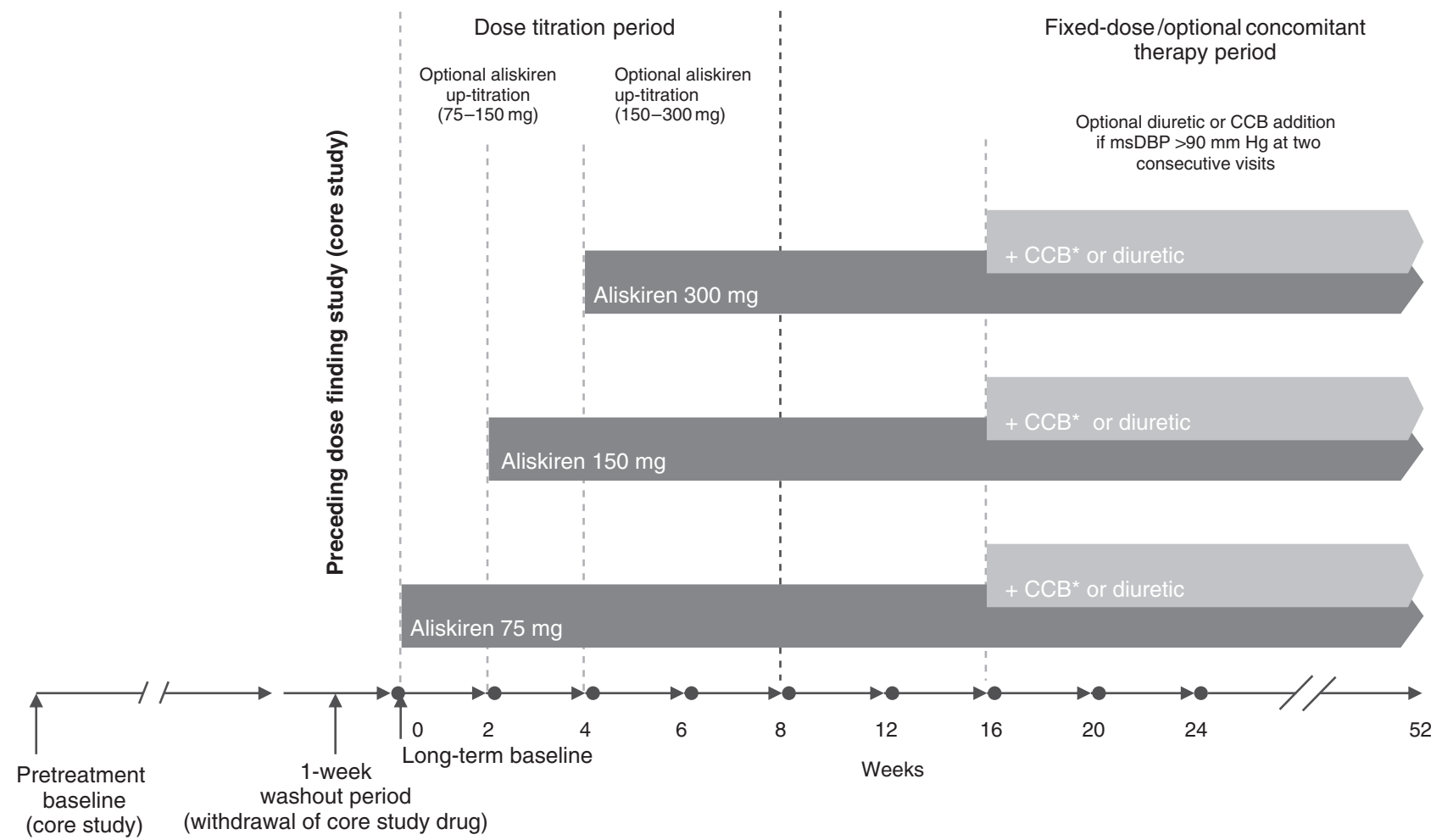

${ }^{*} \mathrm{CCB}$, calcium channel blocker

Figure 1 Study design. 
aliskiren+diuretic, or aliskiren+CCB). The change from the baseline (visit 3 of the dose-finding study; start of the long-term study) in msDBP and msSBP, and the number of responders at consecutive visits were calculated for the entire aliskiren group and each post-dose fixation group. The primary efficacy variable and the secondary efficacy variables were analyzed in the full analysis set, which included all enrolled patients who had an efficacy assessment at the baseline (visit 3 of the dose-finding study) or at the beginning of the open-label study, and at least one post-baseline efficacy measurement during the openlabel treatment period. In the case of missing data, the last post-baseline measurement during the open-label treatment for each patient was carried forward (LOCF) as the end point measurement for the variable to be analyzed. Safety parameters such as AEs were summarized for the safety population, which included all enrolled patients who received the study medication during the open-label period. The laboratory data were summarized at the baseline (day of randomization in the dose-finding study; start of the long-term study) and at all study visits using LOCF. Vital signs and the proportion of patients who experienced orthostatic BP changes (a decrease in at least $20 \mathrm{~mm} \mathrm{Hg}$ in SBP or a decrease in at least $10 \mathrm{~mm} \mathrm{Hg}$ in DBP when a patient moves from a supine position to a standing position) were also reported.

\section{RESULTS}

In this study, 345 patients from the previous dose-finding study were included. One patient withdrew consent without taking the study drug
$(N=344)$ and 45 patients $(13.1 \%)$ discontinued from the study (Figure 2). The proportion of discontinuations was similar in the monotherapy group $(n=26,14.9 \%)$ and combination therapy groups (aliskiren/CCB, $n=9,10 \%$; aliskiren/diuretic, $n=10,12.7 \%$ ). At the end of the study, 175 patients (51\%) were on aliskiren monotherapy and the remaining patients were on the combination therapy (aliskiren/ CCB, $n=90$; aliskiren/diuretic, $n=79$ ). The baseline and demographic characteristics were similar in the three aliskiren dose groups (Table 1). The majority of patients were male $(74.1 \%)$ and $<65$ years $(88.7 \%)$. The proportion of patients who required an optional add-on therapy (a CCB or a diuretic) in the three aliskiren dose groups is given in Table 2 . The most commonly used diuretics were indapamide $(10.2 \%)$ and trichlormethiazide (12.2\%), and the most commonly used CCB was amlodipine (21.5\%). At the study end point, 95 patients (27.5\%) were on aliskiren $75 \mathrm{mg}, 65$ patients $(18.8 \%)$ were on aliskiren $150 \mathrm{mg}$, and 184 patients $(53.3 \%)$ were on aliskiren $300 \mathrm{mg}$. In the aliskiren $300 \mathrm{mg}$ group, one patient was non-compliant. The total median exposure during the study to any dose of aliskiren was 364 days (9-372).

\section{Efficacy}

Clinically meaningful double-digit reductions from the pretreatment baseline in msSBP and msDBP were achieved in all patients $(N=344)$

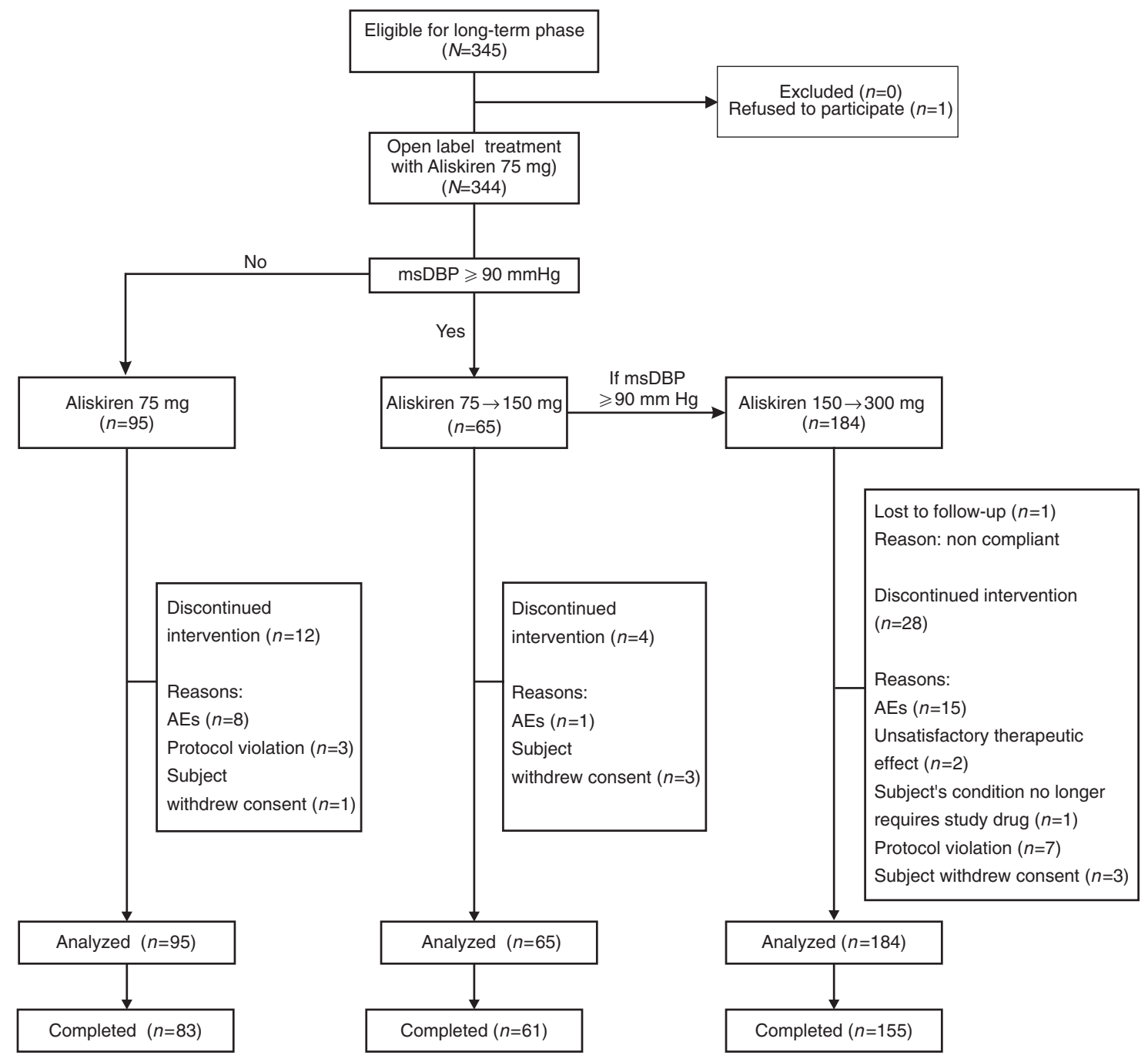

Figure 2 Patient flow diagram. 
Table 1 Patient's baseline and demographic characteristics

\begin{tabular}{|c|c|c|c|c|}
\hline & All treated patients $(\mathrm{N}=344)$ & Aliskiren monotherapy $(\mathrm{n}=175)$ & Aliskiren $+C C B(\mathrm{n}=90)$ & Aliskiren+diuretic $(n=79)$ \\
\hline Age (years), mean (s.d.) & $52.4(9.91)$ & $53.0(10.35)$ & $51.8(8.96)$ & $51.8(9.98)$ \\
\hline$<65$ years & $305(88.7)$ & $151(86.3)$ & $83(92.2)$ & $71(89.9)$ \\
\hline$\geqslant 65$ years & 39 (11.3) & $24(13.7)$ & $7(7.8)$ & $8(10.1)$ \\
\hline \multicolumn{5}{|l|}{ Sex, n (\%) } \\
\hline Female & $89(25.9)$ & $62(35.4)$ & $11(12.2)$ & $16(20.3)$ \\
\hline Weight (kg), mean (s.d.) & $70.2(13.45)$ & $68.0(13.16)$ & $73.6(13.83)$ & $71.4(12.84)$ \\
\hline Height $^{\mathrm{a}}(\mathrm{cm})$, mean (s.d.) & $165.3(8.47)$ & $163.9(8.84)$ & $166.9(6.99)$ & $166.7(8.73)$ \\
\hline $\mathrm{BMI}^{\mathrm{a}}\left(\mathrm{kg} / \mathrm{m}^{2}\right)$, mean (s.d.) & $25.6(3.61)$ & $25.2(3.39)$ & $26.3(3.90)$ & $25.6(3.65)$ \\
\hline \multicolumn{5}{|l|}{$m s D B P(m m ~ H g)$, mean (s.d.) } \\
\hline \multicolumn{5}{|l|}{$m s S B P(m m ~ H g)$, mean (s.d.) } \\
\hline Pretreatment baseline & $154.5(10.94)$ & $152.5(10.28)$ & $156.1(11.46)$ & $157.1(11.05)$ \\
\hline Long-term study baseline & $148.7(14.11)$ & $144.4(13.63)$ & $153.6(11.57)$ & $152.7(14.90)$ \\
\hline
\end{tabular}

Abbreviations: BMI, body mass index; CCB, calcium channel blocker; msDBP, mean sitting diastolic blood pressure; msSBP, mean sitting systolic blood pressure.

aHeight from the dose-finding study. ${ }^{14}$

bPretreatment baseline - before core study when patients were not on antihypertensive therapy. ${ }^{13}$

'Long-term study baseline - start of the present long-term study after 1 week washout period.

Table 2 Concomitant medication usage in the post-dose fixation period

\begin{tabular}{lcccc}
\hline & All treated patients $(\mathrm{N}=344)$ & Aliskiren $75 \mathrm{mg}(\mathrm{n}=95)$ & Aliskiren $150 \mathrm{mg}(\mathrm{n}=65)$ & Aliskiren 300 mg $(\mathrm{n}=184)$ \\
\hline CCBs & $119(34.6)$ & $5(5.3)$ & $18(27.7)$ & $96(52.2)$ \\
Diuretics & $91(26.5)$ & $6(6.3)$ & $11(16.9)$ & $74(40.2)$ \\
\hline
\end{tabular}

Abbreviation: CCB, calcium channel blocker.

exposed to aliskiren irrespective of the dose or treatments received at the study end point. The mean change from the pretreatment baseline before the core study in msDBP (s.d.) was $-12.8 \mathrm{~mm} \mathrm{Hg}$ (8.25), and from long-term baseline after only a 1-week washout was $-7.5 \mathrm{~mm} \mathrm{Hg}$ (9.85). The mean change from the pretreatment baseline in msSBP (s.d.) was $-17.6 \mathrm{~mm} \mathrm{Hg}$ (14.42), and from long-term baseline was $-11.9 \mathrm{~mm} \mathrm{Hg}$ (14.92). Aliskiren monotherapy (at week 8) resulted in $\mathrm{BP}(\mathrm{msSBP} / \mathrm{msDBP})$ reductions of $12.4 / 9.2 \mathrm{~mm} \mathrm{Hg}$ from the pretreatment baseline before the previous dose-finding study, and a reduction of $6.5 / 3.9 \mathrm{~mm} \mathrm{Hg}$ from the long-term baseline just before this study (Figure 3). The mean (s.d.) sitting pulse rate at long-term baseline was $73.3 \pm 9.45$ b.p.m. (beats per minute) in all treated patients and was unchanged at the study end point. Overall responder rate was $73.3 \%$ $(252 / 344)$ at the study end point (Figure 4$)$.

\section{Safety and tolerability}

Long-term aliskiren-based therapy was generally well tolerated. The overall incidence of AEs in this 52-week, long-term study was $85.2 \%$ $(293 / 344)$. AEs suspected to be related to the study drug occurred in $25.3 \%(87 / 344)$ of patients. Most AEs were mild or moderate in intensity, and the incidence of AEs was similar in patients receiving aliskiren alone $(72.7 \%)$ or aliskiren in combination with a CCB $(72.3 \%)$ or a diuretic $(69.2 \%)$.
Few patients discontinued due to AEs (7.0\%), and the rate was slightly higher with the combination therapy than aliskiren monotherapy. The most frequently reported AEs according to the MedDRA (Medical Dictionary for Regulatory Activities) system organ class were infections and infestations (55.5\%), investigations (25.3\%), gastrointestinal disorders (16.0\%), musculoskeletal and connective tissue disorders (16.0\%), and nervous system disorders (10.2\%). The most frequently reported AEs were nasopharyngitis, back pain, seasonal allergies, and laryngopharyngitis (Table 3). Nasopharyngitis was more frequent in all treatment groups in aliskiren studies conducted in Japan. ${ }^{13}$ The incidence of serum potassium levels $<3.5 \mathrm{mmoll}^{-1}$ was higher with the combination therapy $(3.3 \%$ in the aliskiren+CCB group and $2.5 \%$ in the aliskiren+diuretic group) than monotherapy (1.1\%). Orthostatic changes in BP were observed in $<20 \%$ of the overall patients at any time during the study. There were no clinically relevant changes in weight or body mass index during the study. The incidence of serious AEs (SAEs) was low (9/344, 2.6\%) during the study. Two cases $(0.6 \%)$ of rectal cancer were reported, but these were considered by the investigators to be present at the commencement of the study. For three SAEs, a possible relation to the study drug could not be ruled out (brain stem infarction, neoplasm malignant (in one patient with rectal cancer), and acute myocardial infarction). No deaths occurred during the study period. 


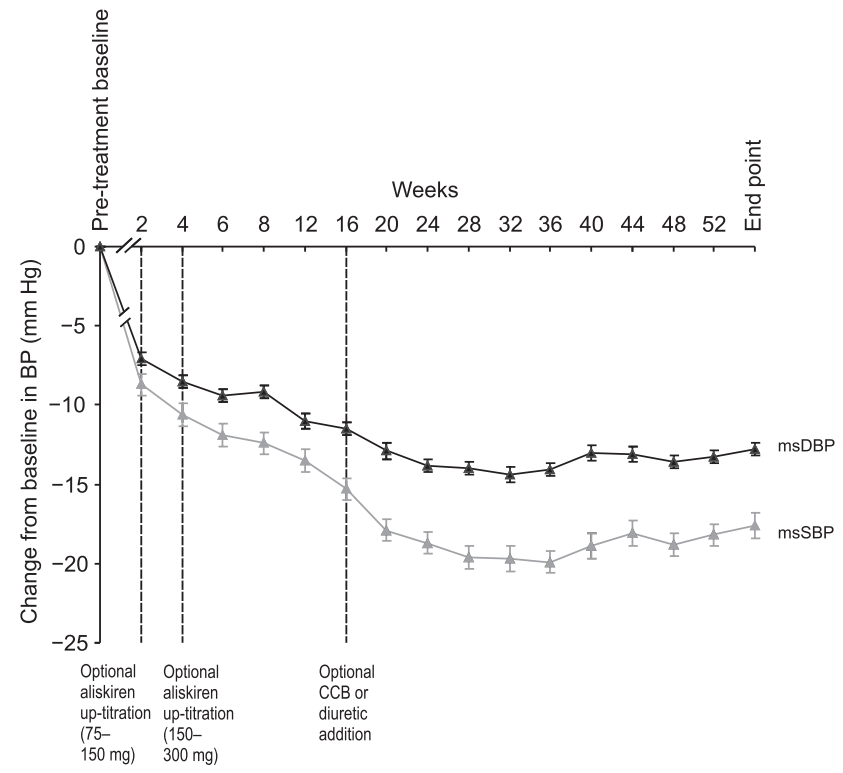

Figure 3 Change in msDBP and msSBP from the pretreatment baseline. End point is week 52 or LOCF. Wk, week; CCB, calcium channel blocker; msSBP, mean sitting systolic blood pressure; msDBP, mean sitting diastolic blood pressure; LOCF, last observation carried forward.

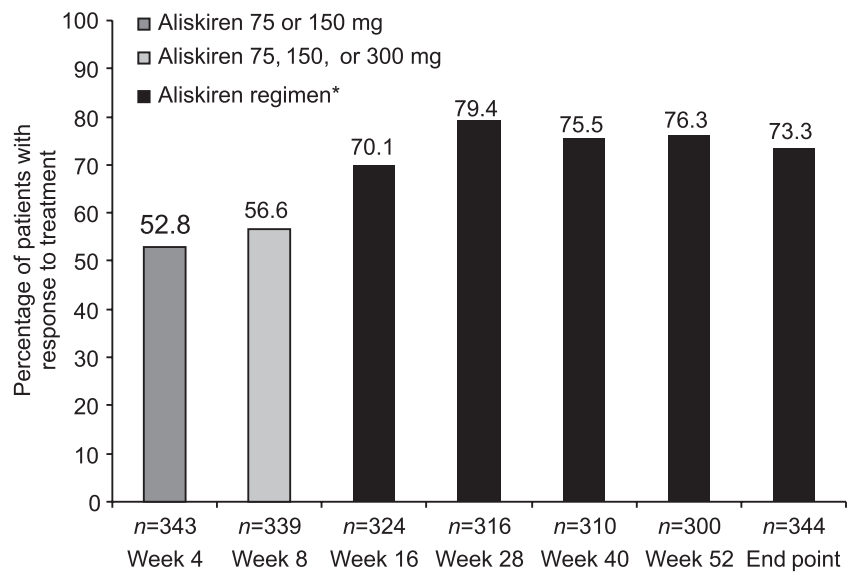

Figure 4 Blood pressure response rates during long-term aliskiren-based therapy. BP response: mean sitting diastolic blood pressure $<90$ and/or $\geqslant 10 \mathrm{~mm} \mathrm{Hg}$ decrease from the pretreatment baseline. End point is week 52 or last observation carried forward. Week 4: aliskiren 75 or $150 \mathrm{mg}$ monotherapy. Week 8: aliskiren 75, 150, or $300 \mathrm{mg}$ monotherapy. *Week 16 to the end point: aliskiren 75,150 , or $300 \mathrm{mg}$ monotherapy and combination therapy with a diuretic or calcium channel blocker.

\section{DISCUSSION}

This long-term study with aliskiren in a Japanese population with mild-to-moderate hypertension was conducted in patients who had completed a previous 8-week parallel-group study of aliskiren 75,150 , $300 \mathrm{mg}$, and placebo. ${ }^{13}$ After a 1-week washout, therapy was initiated for this long-term study at $75 \mathrm{mg}$ aliskiren and titrated as described previously. In the core dose-finding study, aliskiren 75, 150, and $300 \mathrm{mg}$ o.d. significantly reduced mean sitting BP ( $\mathrm{msSBP} / \mathrm{msDBP})$ in a dose-dependent manner as compared with placebo. ${ }^{13}$ In this longterm study with aliskiren, the double-digit reductions in BP from the pretreatment baseline before the core dose-finding study (17.6/ $12.8 \mathrm{~mm} \mathrm{Hg}$ ) were maintained over 52 weeks. Similar reductions (aliskiren monotherapy: 17.4/13.3 mm Hg; aliskiren+HCTZ: $18.7 /$ $12.1 \mathrm{~mm} \mathrm{Hg}$ ) were observed in a 52-week study in Caucasian patients with mild-to-moderate hypertension. ${ }^{15}$ Vaidyanathan et al. ${ }^{16}$ showed similar pharmacokinetic and pharmacodynamic properties of aliskiren in Japanese and Caucasian patients, and this study further confirms that over the long-term there appear to be no significant differences in the efficacy of aliskiren between Japanese and Caucasian patients with hypertension.

Two different baselines were used in this study: (i) the long-term study baseline was used to assess changes during the study and (ii) the pretreatment baseline was used to assess changes from the core study baseline when patients were not on antihypertensive therapy. The pretreatment baseline was used for most of the analyses because of the persistence of the BP-lowering effect of aliskiren after the 1-week washout period between the trials as shown in Table 1. This effect was pronounced in the patients subsequently treated with aliskiren monotherapy and has also been observed in non-Japanese populations with mild-to-moderate hypertension. ${ }^{10,14,15}$

In large clinical studies, approximately two-thirds of patients required the combination therapy to achieve $\mathrm{BP}$ control. ${ }^{17,18}$ In contrast, in this study more than half the patients on the aliskiren monotherapy achieved BP control, whereas the remaining patients required the optional addition of a diuretic or a CCB. Overall, 84 patients (68 patients from $<65$ years age group and 16 patients from $\geqslant 65$ years age group) achieved BP goal according to the Japanese Society of Hypertension guidelines, and over $70 \%$ of the patients responded to aliskiren in this study. Similar responder rates were observed in other studies comparing aliskiren with ramipril (being the most commonly used ACEI outside Japan) in hypertensive patients and in a diabetic population with hypertension. ${ }^{10,19}$

There were no deaths during the study and few SAEs were reported, although a possible relation to the study drug could not be excluded for three patients. The incidence of AEs was similar for both aliskiren monotherapy and aliskiren in combination with a $\mathrm{CCB} /$ diuretic.

The results from this study were consistent with those of the previous studies where aliskiren showed tolerability comparable to placebo at doses up to $300 \mathrm{mg}$ o.d. and had a safety profile equivalent to the ARBs. ${ }^{20,21}$ Similar results were observed in a pooled analysis of data from eight randomized, multicenter studies (8570 patients with mild-to-moderate hypertension), wherein aliskiren showed tolerability comparable to placebo. ${ }^{22}$ The commonly reported AEs with aliskiren were headache, nasopharyngitis, and diarrhea, and these AEs were not significantly different from placebo. ${ }^{22}$ Interestingly, a greater number of patients $(93 \%)$ in the aliskiren $150 \mathrm{mg}$ group completed the study as compared with those in the aliskiren $75 \mathrm{mg}$ group ( $\sim 85 \%)$ mainly because of discontinuations due to side effects. A similar trend has been observed in previous studies in non-Japanese populations. ${ }^{21,23,24}$ The difference may relate to effects caused by the underlying hypertensive state rather than drug-related effects.

The primary goal of treating patients with essential hypertension is to attain target BP levels, thereby reducing long-term risk of cardiovascular morbidity and mortality with minimal side effects. The results of this study showed that long-term use of aliskiren alone and aliskiren in combination with a CCB or a diuretic was well tolerated; moreover, BP goal was attained in the majority of patients. This study adds to the growing evidence that aliskiren, an oral direct renin inhibitor, is effective in the long-term control of hypertension. Further long-term and large-scale studies are needed to prove the endorgan protection benefits of aliskiren. 
Table 3 Incidence of AEs in all treatment groups (safety population)

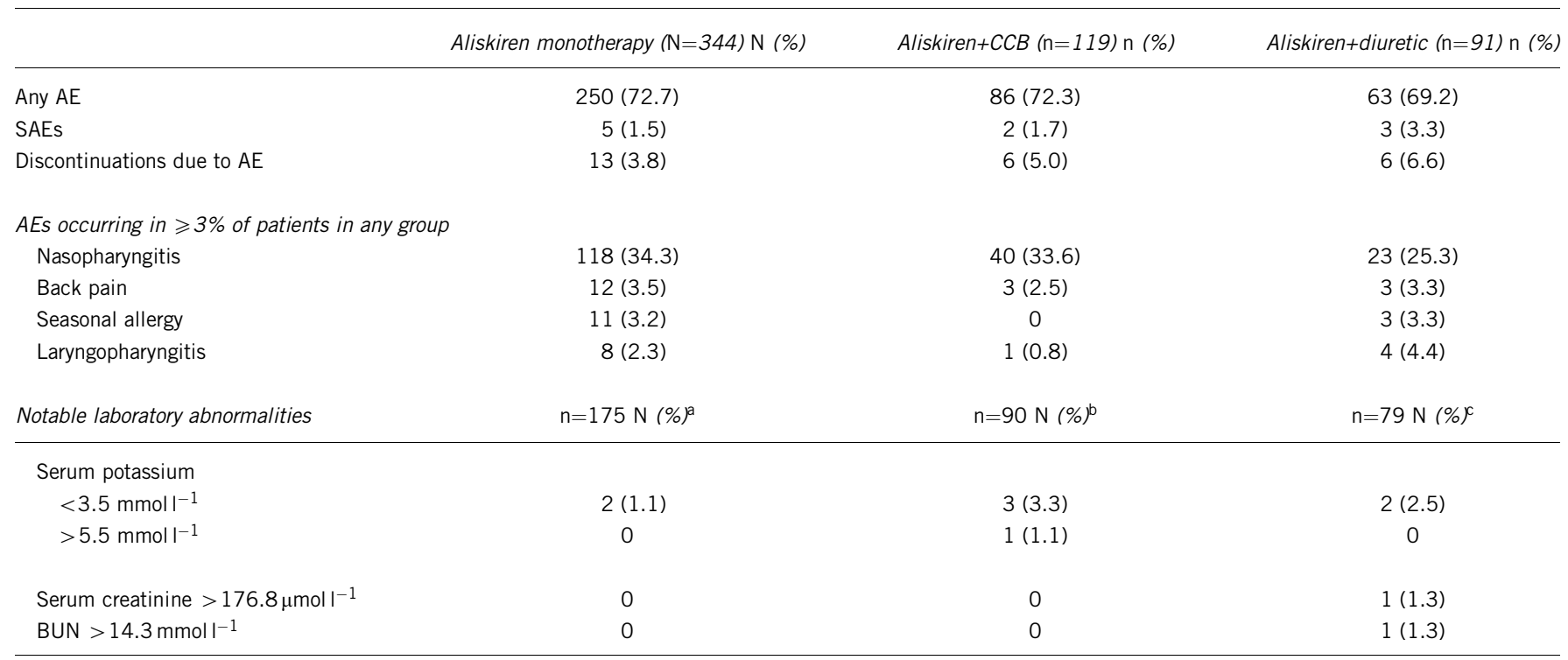

Abbreviations: AE, adverse event; BUN, blood urea nitrogen; CCB, calcium channel blocker; SAE, serious adverse event.

Abbreviations: $A E$, adverse event; $B U N$, blood urea
apatients who received only aliskiren monotherapy.

bPatients who received at least one dose of optional CCB add-on therapy.

cPatients who received at least one dose of optional diuretic add-on therapy.

\section{Conclusion}

Long-term therapy with aliskiren alone or aliskiren in combination with a CCB or a diuretic in Japanese patients with hypertension was well tolerated and provided effective BP reductions that were maintained over 52 weeks of treatment.

\section{ACKNOWLEDGEMENTS}

This study was supported by Novartis Pharma AG (Basel, Switzerland). The authors acknowledge the investigators and other staff members who participated in this study. They also thank Dr Thej Kumar Nallagangula (Novartis) for his assistance in the manuscript preparation.

1 Japanese Society of Hypertension. Japanese Society of Hypertension Guidelines for the Management of Hypertension (JSH 2004). Hypertens Res 2006; 29: S1-S106.

2 Chobanian AV, Bakris GL, Black HR, Cushman WC, Green LA, Izzo Jr JL, Jones DW, Materson BJ, Oparil S, Wright Jr JT, Roccella EJ, National Heart, Lung, and Blood Institute Joint National Committee on Prevention, Detection, Evaluation, and Treatment of High Blood Pressure; National High Blood Pressure Education Program Coordinating Committeelpar. The Seventh Report of the Joint National Committee on Prevention, Detection, Evaluation, and Treatment of High Blood Pressure. JAMA 2003; 289: 2560-2572.

3 Mancia G, De Backer G, Dominiczak A, Cifkova R, Fagard R, Germano G, Grassi G, Heagerty AM, Kjeldsen SE, Laurent S, Narkiewicz K, Ruilope L, Rynkiewicz A, Schmieder RE, Boudier HA, Zanchetti A, ESH-ESC Task Force on the Management of Arterial Hypertension. 2007 ESH-ESC Practice Guidelines for the Management of Arterial Hypertension: ESH-ESC Task Force on the Management of Arterial Hypertension [Guidelines]. J Hypertens 2007; 25: 1751-1762.

4 Fujita T, Wu Z, Park JB, Chen MF. Briefings on JHS, CHS, KHS and THS guidelines and their difference from JNC VII and ESC/ESH. Int J Clin Pract 2006; 60: 3-6.

5 Neutel JM, Smith DH. Improving patient compliance: a major goal in the management of hypertension. J Clin Hypertens 2003; 5: 127-132.

6 Krousel-Wood M, Thomas S, Muntner P, Morisky D. Medication adherence: a key factor in achieving blood pressure control and good clinical outcomes in hypertensive patients. Curr Opin Cardiol 2004; 19: 357-362.

7 Tassell BW, Munger MA. Aliskiren for renin inhibition: a new class of antihypertensives. Ann Pharmacother 2007; 41: 456-464.

8 Azizi M. Renin inhibition: the next step in suppression of the renin-angiotensin system? Curr Hypertens Rep 2007; 9: 81-83.
9 Oparil S, Yarows SA, Patel S, Fang H, Zhang J, Satlin A. Efficacy and safety of combined use of aliskiren and valsartan in patients with hypertension: a randomised, double-blind trial. Lancet 2007; 370: 221-229.

10 Andersen K, Weinberger MH, Egan B, Constance CM, Ali MA, Jin J, Keefe DL. Comparative efficacy and safety of aliskiren, an oral direct renin inhibitor, and ramipril in hypertension: a 6-month, randomized, double-blind trial. J Hypertens 2008; 26: 589-599.

11 Drummond W, Munger MA, Rafique Essop M, Maboudian M, Khan M, Keefe DL. Antihypertensive efficacy of the oral direct renin inhibitor aliskiren as add-on therapy in patients not responding to amlodipine monotherapy. J Clin Hypertens (Greenwich) 2007; 9: 742-750.

12 Villamil A, Chrysant SG, Calhoun D, Schober B, Hsu H, Matrisciano-Dimichino L, Zhang J. Renin inhibition with aliskiren provides additive antihypertensive efficacy when used in combination with hydrochlorothiazide. Hypertension 2007; 25: 217-226.

13 Kushiro T, Itakura H, Abo Y, Gotou H, Terao S, Keefe DL. Aliskiren, a novel oral renin inhibitor, provides dose-dependent efficacy and placebo-like tolerability in Japanese patients with hypertension. Hypertens Res 2006; 29: 997-1005.

$14 \mathrm{Oh} \mathrm{BH}$, Mitchell J, Herron JR, Chung J, Khan M, Keefe DL. Aliskiren, an oral renin inhibitor, provides dose-dependent efficacy and sustained 24-hour blood pressure control in patients with hypertension. J Am Coll Cardiol 2007; 49: 1157-1163.

15 Sica D, Gradman AH, Lederballe O, Meyers M, Cai J, Keefe DL. Aliskiren, a novel renin inhibitor, is well tolerated and has sustained BP-lowering effects alone or in combination with HCTZ during long-term (52 weeks) treatment of hypertension [abstract]. Eur Heart J 2006; 27: P797.

16 Vaidyanathan S, Jermany J, Yeh C, Bizot MN, Camisasca R. Aliskiren, a novel orally effective renin inhibitor, exhibits similar pharmacokinetics and pharmacodynamics in Japanese and Caucasian subjects. Br J Clin Pharmacol 2006; 62: 690-698.

17 Black HR, Elliott WJ, Neaton JD, Grandits G, Grambsch P, Grimm Jr RH, Hansson L, Lacoucière $Y$, Muller J, Sleight $P$, Weber MA, White WB, Williams G, Wittes J, Zanchetti A, Fakouhi TD, Anders RJ. Baseline characteristics and early blood pressure control in the CONVINCE trial. Hypertension 2001; 37: 12-18.

18 Cushman WC, Ford CE, Cutler JA, Margolis KL, Davis BR, Grimm RH, Black HR, Hamilton BP, Holland J, Nwachuku C, Papademetriou V, Probstfield J, Wright Jr JT, Alderman MH, Weiss RJ, Piller L, Bettencourt J, Walsh SM, ALLHAT Collaborative Research Group. Success and predictors of blood pressure control in diverse North American settings: the antihypertensive and lipid-lowering treatment to prevent heart attack trial (ALLHAT). J Clin Hypertens (Greenwich) 2002; 4: 393-404.

19 Uresin Y, Taylor A, Kilo C, Tschope D, Santonastaso M, Ibram G, Fang H, Satlin A. Aliskiren, a novel renin inhibitor, has greater BP lowering than ramipril and additional BP lowering when combined with ramipril in patients with diabetes and hypertension [Abstract]. J Hypertens 2006; 24: S82.

20 Gradman AH, Schmieder RE, Lins RL, Nussberger J, Chiang Y, Bedigian MP. Aliskiren, a novel orally effective renin inhibitor, provides dose-dependent antihypertensive efficacy and placebo-like tolerability in hypertensive patients. Circulation 2005; 111: 1012-1018.

21 Stanton A. Therapeutic potential of renin inhibitors in the management of cardiovascular disorders. Am J Cardiovasc Drug 2003; 3: 389-394. 
22 Weir MR, Bush C, Zhang J, Keefe DL, Satlin A. Antihypertensive efficacy and safety of the oral renin inhibitor aliskiren in patients with hypertension: a pooled analysis [abstract]. Eur Heart J 2006; 27: 299.

23 Pool JL, Schmieder RE, Azizi M, Aldigier JC, Januszewicz A, Zidek W, Chiang Y, Satlin A. Aliskiren, an orally effective renin inhibitor, provides antihypertensive efficacy alone and in combination with valsartan. Am J Hypertens 2007; 20: 11-20.

24 Verdecchia P, Calvo C, Möckel V, Keeling L, Satlin A. Safety and efficacy of the oral direct renin inhibitor aliskiren in elderly patients with hypertension. Blood Press 2007; 16: 381-391.

\section{LIST OF STUDY CENTERS AND INVESTIGATORS}

M Sugiura, Medical Corporation Tsunematsukai, Toei Hospital; T Ashida, Marunouchi Hospital, The Institute for Adult Diseases, Asahi Life Foundation; H Itakura, Iryohojin Shadan Jozenkai, Shinagawa East One Medical Clinic; G Uchiura, Shinagawa East Medical Clinic; I Miho, Iryohojin Shadan Yuhokai Miho Clinic; K Suzuki, Kenkokan
Suzuki Clinic; Y Abo, Iryohojin Shadan DAP, Kita-Aoyama D Clinic; H Shimomura, Junyokai Musashino Clinic; K Okamoto, Towakai Shinozaki Ekimae Clinic; H Natomi, Tokyo Life Clinic; A Numata, Ikebukuro Metropolitan Clinic; K Takada, Shibuya Mark City Takada Clinic; S Kondo, Tokyo Clinical Research Organization for Medicine Clinic; H Tajima, Hakuseikai Tajima Clinic; J Yamagami, Yamagami Medical Clinic; T Kurata, Kurata Clinic; H Tei, Iryohojin Takahashi Clinic of Internal Medicine; S Yano, Maebashi Hirosegawa Clinic; S Sugimoto, Ryokuseikai Sugimoto Hospital; I Kobayashi, Kobayashi Internal Medicine and Gastroenterology Clinic; Y Niijima, Kan-etsu Chu-oh Hospital; H Tsuchida, Seijunkai Johoku Hospital; H Yoshida, Medoc Kenko Clinic; T Kawashima, Kasugakai Kawashima Clinic; M Kondo, Kondo Clinic; S Kajiyama, Kajiyama Clinic; H Ameno, Shoyukai Ameno Clinic; Y Furuta, Kobe Kaisei Hospital; M Hiraga, Keiaikai Nakamura Hospital; Y Tatsukawa, Keiwakai Oita Oka Hospital. 